\title{
SENTIMENTOS DE MULHERES-MÃES DIANTE DA CIRURGIA NEONATAL NAS MALFORMAÇÕES CONGÊNITAS
}

\author{
The feelings of women-mothers faced with the surgery in newborn birth defects \\ Sentimientos de mujeres-madres delante de la cirugía neonatal en las malformaciones \\ congénitas
}

Adriana Teixeira Reis ${ }^{1}$

Rosângela da Silva Santos ${ }^{2}$

\section{RESUMO}

0 estudo buscou compreender os sentimentos vivenciados por mulheres-mães diante da cirurgia neonatal de seus filhos, portadores de malformações congênitas. Trata-se de uma pesquisa qualitativa, baseada no método história de vida. Utilizou a entrevista aberta entre 18 mulheres-mães de recém-nascidos submetidos a procedimentos cirúrgicos no período neonatal. A coleta de dados foi realizada entre julho e agosto de 2009. A análise temática das narrativas apontou para a expectativa de "normalização" da criança e das trajetórias de vida das mulheres. A experiência de hospitalização é ambígua: ao passo que desejam e criam grande expectativa perante o ato cirúrgico, sentem-se em conflito com múltiplos medos (da morte, da anestesia e da cronicidade). No processo de cuidado aos portadores de malformações congênitas cirúrgicas, a enfermagem deve considerar não apenas a visão técnica, mas, sobretudo, os sentimentos ambíguos expressos pelas mulheres-mães, em uma importante fase de construção de vínculos afetivos junto ao seu filho.

Palavras-chave: Enfermagem Obstétrica. Enfermagem Neonatal. Mães. Anormalidades Congênitas. Cirurgia.

\begin{abstract}
Abstract: The study sought to understand the feelings experienced by women-mothers of neonatal surgery on his children, patients with congenital malformations. This is a qualitative research method based on the life history. We used structured interviews with eighteen women, mothers of infants undergoing surgical procedures in the neonatal period. Data collection was conducted between July and August 2009. The thematic analysis of narratives pointed to the expectation of "normalization" of the child and the life trajectories of women. Hospital admission is ambiguous: while wishing to create great expectations and forward to the surgery, they feel in conflict with multiple fears (of death, anesthesia, and chronicity). In the process of care to patients with congenital surgical malformations nursing must consider not only the technical view, but above all, the ambiguous feelings expressed by womenmothers, in an important phase of building emotional bonds with your child.
\end{abstract}

Keywords: Obstetrical nursing. Neonatal nursing. Mothers. Congenital abnormalities. Surgery.

\section{Resumen}

El estudio trata de comprender los sentimientos que experimentan las mujeres-madres frente a la cirugía neonatal de los hijos, los pacientes con malformaciones congénitas. Este es un estudio cualitativo basado en el método historia de vida. Utilizó la entrevista grabada entre dieciocho mujeres, las madres de recién nacidos sometidos a procedimientos quirúrgicos en el período neonatal. La recolección de datos se llevó a cabo entre julio y agosto de 2009. El análisis temático de las narrativas señaló que la expectativa de "normalización" de los niños y las trayectorias de vida de las mujeres. La experiencia de hospitalización es ambigua: al mismo tiempo que deseen para crear grandes expectativas y lo remitirá a la cirugía, se sienten en conflicto con varios temores (de la muerte, la anestesia y la cronicidad). En el proceso de atención a pacientes con malformaciones congénitas quirúrgicas, la enfermería debe considerar no sólo el punto de vista técnico, pero sobre todo, los sentimientos de ambigüedad expresados por las mujeres-madres, en una fase importante de la construcción de vínculos afectivos con su hijo.

Palabras-clave: Enfermería obstétrica. Enfermería neonatal. Madres. Anomalías congénitas. Cirugía.

${ }_{11}^{11}$ Doutora em Enfermagem. Tecnologista em Saúde Pública do Departamento de Cirurgia Pediátrica do Instituto Fernandes Figueira- FIOCRUZ. Professora Assistente do Departamento de Enfermagem Materno-Infantil da Faculdade de Enfermagem da Universidade do Estado do Rio de Janeiro. Rio de JaneiroRJ. Brasil. E-mail: driefa@terra.com.br;'Doutora em Enfermagem. Docente Permanente do Programa de Pós-Graduação em Enfermagem da Escola de Enfermagem Anna Nery/UFRJ. Professora Adjunta do Departamento de Enfermagem Materno-Infantil da Faculdade de Enfermagem da Universidade do Estado do Rio de Janeiro. Rio de Janeiro-RJ. Brasil. E-mail: rosangelaufrj@gmail.com 


\section{INTRODUÇÃO}

Cerca de $2 \%$ a $4 \%$ de nascidos vivos apresentam algum tipo de malformação detectada ao nascimento. Na cidade do Rio de Janeiro, Brasil, as malformações congênitas compõem a segunda causa de mortalidade infantil, perfazendo $15 \%$ da mortalidade em 2000 e $18 \%$ em 2003 entre menores de 1 ano. ${ }^{1}$

Graças aos avanços da medicina perinatal, a sobrevida de bebês portadores destas malformações melhorou consideravelmente nos últimos anos. ${ }^{2} 0$ aumento dessa sobrevida coincidiu com o avanço de técnicas cirúrgicas e novos recursos terapêuticos que têm contribuído para a correção de anomalias operáveis (ou cirurgicamente corrigíveis). ${ }^{3}$

Tais avanços disponibilizaram a realização de exames diagnósticos cada vez mais precisos, ampliando a detecção de malformações congênitas ainda no pré-natal, de forma que a cirurgia fetal tem sido considerada exitosa e com certo poder para melhorar a qualidade de vida de algumas crianças. ${ }^{4}$

Graças a essas transformações, o perfil de atenção em unidades especializadas de atendimento materno-infantil tem sido modificado. No cotidiano assistencial da enfermagem, observamos contatos cada vez mais precoces com mulheres $e$ familiares de crianças com diagnósticos de malformações que requerem intervenções cirúrgicas.

Uma cirurgia na vida neonatal requer suporte em Unidade de Terapia Intensiva Neonatal (UTIN), o que demanda maior desgaste emocional da mulher, que convive com inúmeras incertezas sobre a saúde e a (im)possibilidade de sobrevivência do bebê. Apesar da importância desta temática, o estresse de pais de RN cirúrgicos internados em UTIN é um campo de estudo pouco explorado. ${ }^{5}$

Para a mulher-mãe, a vivência do diagnóstico de malformação, da necessidade de cirurgia no recém-nascido (RN) e sua hospitalização na UTIN disparam um rol de dúvidas que gera sentimentos conflituosos de rejeição, medo e culpa, todos esses geradores de intenso sofrimento psíquico. A mulher precisa desconstruir suas crenças, valores e aspirações idealizados, passando a ser assolada por uma série de informações científicas, o que torna esse momento assustador e angustiante para ela e sua família. Mesmo em situações "normais", algumas mulheres, durante o contato com o bebê, demonstram certa apreensão com as características apresentadas por ele logo após o nascimento. ${ }^{6}$ Imaginemos 0 quão é difícil para a mulher que vivencia esta condição especial: a malformação e a necessidade de cirurgia neonatal.

Nesta perspectiva, este estudo objetivou compreender, na visão de mulheres-mães, os sentimentos vivenciados diante da cirurgia de RN portadores de malformações congênitas, de forma a oferecer subsídios para a promoção de uma prática assistencial sensível, voltada para as necessidades da mulher, enquanto "ambiente" necessário ao desenvolvimento do RN.
Utilizamos o conceito de "ambiente" a partir de Winnicott ${ }^{7}$, neste recorte, entendendo que a mãe é o grande "ambiente" de facilitação para a construção pessoal do ser humano. Do ponto de vista do bebê, nada existe além dele próprio, e, portanto, a mãe faz parte dele. É da relação saudável entre a mãe e o bebê que emergem as bases da formação da personalidade e do desenvolvimento emocional e afetivo da criança. Na fase neonatal, o bebê é um ser humano, imaturo e extremamente dependente, e também um indivíduo que está tendo e armazenando experiências. ${ }^{7}$

Buscar o entendimento desta situação especial (uma correção cirúrgica na presença de uma malformação) visa à compreensão de um momento singular na vida da mulher-mãe, que pode ser mediado por fatores que interferem diretamente no processo de criação do vínculo entre mãe e filho.

\section{MÉTODO}

Trata-se de uma pesquisa qualitativa exploratória e descritiva, desenvolvida com uso do método história de vida. ${ }^{8} 0$ método permitiu estreita aproximação das pesquisadoras com o objeto de estudo e o entendimento da história individual e coletiva destes atores sociais. Bertaux ${ }^{8}$ afirma que, nas Ciências Sociais, o relato de vida é resultado de uma forma peculiar de entrevista, a entrevista narrativa em que um investigador pede a uma pessoa que conte toda ou parte de sua "experiência vivida".

Todas as exigências da Resolução 196 foram atendidas. 0 projeto foi aprovado pelos Comitês de Ética da Escola de Enfermagem Anna Nery/HESFA e do Instituto Fernandes Figueira, através dos protocolos 19/2009 e 0030.0.008.22609, respectivamente.

Para a coleta das narrativas, utilizou-se a técnica da entrevista aberta, mediada pela seguinte questão: "Faleme a respeito de sua vida que tenha relação com a cirurgia de seu filho", em uma amostra aleatória por conveniência, composta por dezoito mulheres-mães de crianças submetidas à cirurgia neonatal devido à existência de uma ou mais malformações congênitas. As mulheres foram captadas de forma intencional, coincidindo com a presença da pesquisadora no Departamento de Cirurgia Pediátrica de uma instituição pública federal, referência para malformações cirurgicamente corrigíveis. 0 Departamento é composto pelos seguintes setores: UTIN Cirúrgica, Enfermaria de Cirurgia e Ambulatório. As entrevistas foram realizadas em local reservado, onde as depoentes puderam ficar à vontade para falar. As narrativas foram gravadas em equipamento Moving Picture Experts Group 1 Audio Player 3 (MP3). Não houve tempo preestabelecido para a gravação.

A coleta dos dados se encerrou à medida que ocorreu 0 "ponto de saturação", isto é, quando as entrevistas não trouxeram mais valor agregado ao conhecimento sociológico do objeto social. ${ }^{8}$ 
As dezoito depoentes foram identificadas por nomes de deusas, garantindo-lhes 0 anonimato. Escolheram os nomes que apresentaram maior afinidade com seu significado. Apenas uma depoente recusou-se a escolher o nome de deusa para identificação como codinome, justificado pela sua opção religiosa. Sua vontade foi respeitada, e ela foi identificada pelo codinome "Estrela", como proposto pela própria.

As idades das mulheres-mães variaram de 16 a 40 anos, sendo a média de 24,5 anos. A idade dos bebês variou entre 9 e 150 dias ( 5 meses) de vida. Foi obtida assinatura e autorização da responsável legal pela depoente de 16 anos (sua mãe). As patologias de maior prevalência entre os bebês foram malformaç̃̃es do trato gastrointestinal $(13 ; 72 \%)$ e anomalias do trato geniturinário $(5 ; 28 \%)$.

Para análise das narrativas, foi utilizada a técnica da análise temática. Nesta técnica, o pesquisador agrupa os dados por temas e examina todos os casos no estudo para ter certeza de que todas as manifestações foram incluídas e comparadas. ${ }^{9}$ Das narrativas emergiram três categorias temáticas: A busca pela "normalização" da criança; A experiência da hospitalização pela necessidade da cirurgia neonatal; Uma vivência de múltiplos medos.

0 método história de vida é caracterizado por uma análise multirreferencial. As histórias de vida, impregnadas de múltiplas facetas, foram analisadas sob a ótica de teóricos que responderam à diversidade dos depoimentos e experiências vivenciadas, tais como Winnicott ${ }^{7}$ e Canghilhem. ${ }^{10}$

\section{RESULTADOS E DISCUSSÃO}

A partir do conhecimento e da indicação de cirurgia no recém-nascido, abre-se um leque de preocupações desconhecidas e possibilidades para a mulher-mãe e a família: "quando será a cirurgia?", "como será a cirurgia?", "o bebê pode morrer?". Nesse turbilhão de sentimentos, a mulhermãe se depara com uma série de informações técnicas, de difícil compreensão. 0 filho gerado, antes da cirurgia, ainda não é considerado um ser reconhecido na vida da família. Houve o nascimento biológico, mas não o social. A aceitação social e a formação da família podem vir a acontecer com a correção cirúrgica ou não. De qualquer forma, a cirurgia parece ser a solução de todos os problemas e grandes expectativas são depositadas neste procedimento.

\section{A busca pela "normalização" da criança}

Na medicina, o estado normal do corpo humano é o estado que se deseja restabelecer. A chamada "normatividade biológica" é a condição em que tudo deve funcionar perfeitamente dentro de regras, seja morfológica ou funcionalmente. Tudo o que sai da regra é anormal ou anômalo. Entretanto, anormal, não é patológico, faz parte da diversidade. ${ }^{10}$ Na presença de malformações que necessitam de correção cirúrgica imediata, a anomalia passa a ser patológica, já que pode interferir na sobrevida da criança. Tratase da reprodução do conceito de corpo como um motor de combustão interna ou como uma máquina movida à bateria. ${ }^{11}$ A mulher espera, então, com ansiedade, que o que está anômalo seja consertado.

Eu estou torcendo pra que essa cirurgia dê certo. Eu estou numa contagem regressiva na minha cabeça assim: vai, vai! (Radha, 19 anos, mãe de uma menina portadora de gastrosquise e atresia de íleo terminal)

0 que as mulheres-mães almejam é que a causa que leva à anormalidade seja totalmente corrigida, extirpada, eliminada, e a cirurgia traz essa esperança. Apostam tudo neste momento.

0 ato cirúrgico torna-se, assim, a grande solução dos problemas e, além de reconstruir o defeito físico e orgânico, parece ter um "poder" de restauração da própria vida da criança e da família, devolvendo o direito de ser mãe e resgatando a construção da família. 0 medo desta solução pode até existir, mas a expectativa de "extirpar o mal", "consertar" ou "corrigir o defeito", considerando o corpo como uma máquina, o supera:

mas aí depois os médicos foram falando que não era nada demais, que era uma cirurgia que depois ela ia ficar normal, tal, aí eu fiquei mais aliviada, mais calma. (Iris, 36 anos, mãe de uma menina portadora de imperfuração anal, persistência de cloaca e duplicação intestinal)

E agora a expectativa que eu tenho é que passe muito rápido esses dois anos pra que ele venha consertar o canal; consertar os ureteres que estão tortos, voltar a fazer xixi normal e fazer plástica na barriguinha pra tirar o excesso de pele [...] (Eirene, 26 anos, mãe de um menino portador de Prunne Belly e ureterostomia bilateral)

As narrativas corroboram o observado por outros autores. ${ }^{12}$ A cirurgia revela-se como um caminho de possibilidades, de vir-a-ser mãe, vir-a-ser filho e vir-a-ser família na sociedade. Enquanto a mulher vivencia o momento de vir-aser, ainda não se reconhece como sendo mãe, nem o bebê como sendo filho. Essa construção da identidade social é progressiva ou até mesmo pode ter o desfecho de não ser, com a morte ou rejeição do bebê.

A concepção de doença compreendida como oposto qualificativo de saúde e a concepção positivista que deriva quantitativamente do estado normal levam à convicção de se poder restaurar cientificamente o normal, anulando a condição patológica. ${ }^{10}$ Assim, a cirurgia é uma estratégia de restauração da condição de normalidade da criança. Saber que uma 
possibilidade para tentativa de cura foi oferecida no plano terapêutico traz alívio e renova as esperanças maternas de normalização do filho:

De saber que ela não vai ficar com problema, com defeitozinho, que ela vai ficar tudo certinho no lugar[...] fazer essa cirurgia já foi mais um alívio pra gente por saber que ela vai pode ser uma criança legal, sem problema nenhum[...] (Iris, 36 anos, mãe de uma menina portadora de imperfuração anal, persistência de cloaca e duplicação intestinal)

A entrega de toda a esperança na recuperação do filho, através do ato cirúrgico, pode ser compreendida como um fenômeno social, em que se acredita que a ciência tem o poder de resolver todos os males, uma vez que o modelo cartesiano do dualismo mente/corpo levou à metáfora do corpo como uma máquina e à divisão conceitual entre corpo e alma, retirando o corpo do jugo da religião e colocando-o firmemente nas mãos da ciência. ${ }^{11}$

A enfermagem pode auxiliar no suporte e facilitação da adaptação seja na acolhida, durante a internação e na alta destas famílias, tornam-se agente facilitador e promotor da escuta. Promover um diálogo aberto, deixar falar, é tecnologia esquecida no cotidiano da assistência de enfermagem, mas que merece resgate para o desempenho de um cuidado de enfermagem sensível e humanizado.

\section{A experiência da hospitalização pela necessidade da cirurgia neonatal}

Realizar o procedimento cirúrgico requer hospitalização do bebê e da mãe. A hospitalização é uma condição que remete sentimentos de tristeza, ansiedade, depressão e abandono da vida pessoal. Tudo isso gera grande sofrimento psíquico que é desestruturante para a mulher e a família. ${ }^{13,14}$ Diké ilustra estes sentimentos em sua narrativa:

A enfermeira: 'Mãe, você sabe que ele vai operaro outro rim?' Aí eu caí no choro de novo[...] Caí em depressão! [...]chorei; minha cunhada ficou conversando comigo um tempão por telefone e eu achando que não estava merecendo aquilo [...].(Diké, 28 anos, mãe de um menino portador de hidronefrose, secundária à estenose ureteral)

As experiências de hospitalização anteriormente vividas podem contribuir para a exacerbação ou redução do medo da morte. No caso de Themis, relembrar a morte do sobrinho foi um agravante:

Eu tinha maior medo de ela vir aqui pra esse hospital porque meu sobrinho ficou internado aqui e morreu[...] (choro) e eu jurei pra mim mesma que nunca entrava aqui mais .... aí minha filha precisa entrar[....] (choro) (Themis, 26 anos, mãe de uma menina portadora de atresia de esôfago)

A solidão e o distanciamento dos familiares potencializam os sentimentos de insegurança:

Mas o tempo que fiquei aqui aprendi muita coisa, mas também foi difícil ficar longe da minha família [...]longe de todo mundo e passar por isso praticamente sozinha.(Ananke, 19 anos, mãe de um menino portador de hidronefrose)

Por vezes, a rotina institucional composta por regras rígidas fazem com que o laço familiar se torne fragilizado. $A$ mulher precisa de amparo emocional diante da vivência cirúrgica neonatal. Assim, flexibilizar algumas rotinas como 0 acompanhamento da mulher por algum familiar pode ser uma estratégia para a redução e apoio aos sentimentos negativos vivenciados.

Por outro lado, a hospitalização também se configura como um difícil espaço de aprendizado, seja sobre os cuidados com o filho, seja de vida:

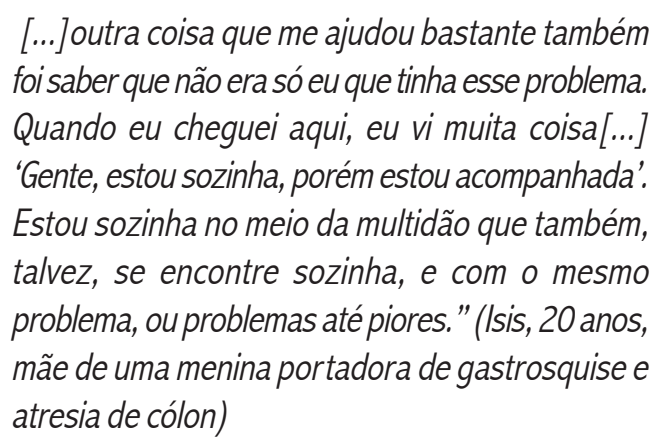

Embora sozinhas, cada qual com suas histórias, encontram espaços para a troca de vivências similares. Estes espaços devem ser garantidos nas instituições e pela equipe de enfermagem, pois tornam-se momentos de trocas de experiências, funcionando, também, como uma rede de apoio institucional à mulher.

A equipe de enfermagem deve trabalhar para a promoção de ações de manutenção e melhoria das condições de saúde do RN, da mulher e sua família. Entendemos aqui a saúde a partir de uma visão ampliada, que visa o bemestar da mulher enquanto "ambiente" indispensável ao RN e dos familiares envolvidos no processo de tratamento cirúrgico da criança.

\section{Uma vivência de múltiplos medos}

Diante de uma situação ameaçadora e desconhecida, surgem vários medos. 0 medo é um sentimento recorrente nas narrativas e é de várias ordens. Está associado ao preconceito social, ao medo da morte, da cirurgia, da anestesia e da cronicidade. 
0 medo do preconceito e o seu enfrentamento social desdobram-se em uma grande preocupação com a estética da criança. A estética é influenciada pela cultura e pelos padrões sociais. Sequelas estéticas têm forte influência no comportamento do indivíduo, pois geram estranheza e chacota pelos outros, causando sentimento de vergonha. ${ }^{15} \mathrm{~A}$ vergonha, em si, é um sentimento social fundamentado nas relações que o indivíduo tem com o grupo e pode ser exacerbada ou diminuída de acordo com as exigências sociais. Eirene expressa essa "dinâmica" social no seguinte trecho:

Por que não é mole, não!! [risos]. É muito diferente. As pessoas sempre perguntam, né? Eu não tenho nenhum problema em explicar porque que meu filho usa cinta. Toda vez que eu vou trocar ele, sempre vem um e pergunta 'mas por que isso? Por que a barriga dele é assim enrugada? Por que esses furinhos atrás?' Eu não tenho problema nenhum em explicar, eu explico[...] No começo era difícil. No começo eu tinha vergonha de trocar a fralda dele, não deixava ninguém vê-lo, me escondia, fechava a porta do quarto, mas depois eu vi que isso ébesteira e que eu tenho que encarar o problema de frente. (Eirene, 26 anos, mãe de um menino portador de Prunne Belly e ureterostomia bilateral)

Pessoas com mutilações e deformidades estão sujeitas à exclusão social. Certas deformidades podem beirar a fronteira da monstruosidade, gerando mal-estar, favorecendo a instalação da infelicidade, principalmente se não podem ser escondidas. ${ }^{15}$

A forma de expressar a gastrosquise do seu filho com a exteriorização de órgãos assume um aspecto de dilaceração:

Mas pra mim meu filho ia nascer bem, perfeito, aí por isso que pra mim foi um (baque) [...]minha pressão subiu, eu fiquei muito mal[...]muito mal[...] da minha mãe chegar ao ponto até de ir na clínica $\mathrm{e}$ quase...quase agredir o meu médico, né? Por conta de ver o neto, vamos dizer[...]dilacerado[...] (Lakshmi, 28 anos, mãe de um menino portador de síndrome do intestino curto, secundária à gastrosquise)

Para Radha, uma adolescente, o impacto da estética é fortemente sentido quando pensa na possibilidade de apresentação de sua filha ao grupo social que pertence. A cultura do corpo esteticamente perfeito, da beleza, está muito presente principalmente nesta fase da vida, e a adolescente vem a sentir essa pressão social seja pela mídia ou mesmo pelos seus pares:

[...] eu não quero que ela fique com gastrostomia [...] aí eu estava preocupada: "poxa, aí em casa vai ver minha filha com esse negócio'[...] ]eu tenho um sentimento estranho: eu não quero que minhas amigas cheguem lá pra ver ela, aí tem que ficar explicando para os outros?Eu não![...] Quero que ela vá pra casa que nem uma criança normal, comendo pela boca, só isso. (Radha, 19 anos, mãe de uma menina portadora de gastrosquise e atresia de íleo terminal)

Nesta situação, é evidente que a maternidade é encarada como um evento social, principalmente para a adolescente que apresenta tendências grupais, típicas desta fase do desenvolvimento humano.

Ainda hoje, a mesma sociedade que acolhe também discrimina o que não é considerado normal. Existe uma cisão entre o corpo "habilitado" e o "desabilitado", o que acaba por rotular os indivíduos, norteando a criação de estigmas sociais, preconceitos e discriminações. ${ }^{11}$ Os estigmas podem ser diminuídos ou potencializados, dependendo da influência cultural.

0 RN cirúrgico é uma clientela muito particular, pois além de requerer internação na UTIN pela sua condição clínica, é mais suscetível ao ato cirúrgico e anestésico pela sua imaturidade orgânica, tornando-o mais vulnerável a estes procedimentos terapêuticos. A vivência da cirurgia e do ato cirúrgico em si gera medo da morte e da perda, presente em 12 narrativas. É um momento marcado pelas incertezas e pela gravidade ainda desconhecida:

Ah, medo de perder ele [choro]. (Ananke, 19 anos, mãe de um menino portador de hidronefrose)

Aí ele chegou aqui e eu fiquei assim...fui pra casa, mas, com medo [...]. Medo de ele não voltar [pausa e choro]. (Cibele, 16 anos, mãe de um menino portador de gastrosquise)

Medo de ele entrar e não voltar, é isso [choro]. (Lakshimi, 28 anos, mãe de um menino portador de síndrome do intestino curto, secundária à gastrosquise)

0 medo é um sentimento que ultrapassa o sofrimento psíquico e é vivenciado, também, com sintomas de adoecimento físico:

quando soube que ele ia operar, eu também tive febre, diarreia; fiquei muito doente lá na maternidade [...] Fiquei com 40 graus de febre, tive diarreia, quase uma semana [...]. Foi mais emocional, preocupação da cirurgia e pela minha família estar longe. (Ananke, 19 anos, mãe de um menino portador de hidronefrose) 
0 medo da anestesia também é relembrado na fala de Eva:

Esse negócio de anestesia me preocupa muito. Tem gente que já morreu por causa da anestesia. (Eva, 40 anos, mãe de um menino portador de síndrome de Down e atresia duodenal)

A vivência do dia-a-dia da internação do bebê na UTIN reforça o medo da perda. Estar em uma UTI não garante a sobrevivência do filho. Pelo contrário, é um ambiente onde o medo da perda é reforçado pelo uso de tecnologias assistenciais duras, chocantes aos leigos olhos das mães:

Cada momento que eu ficava perto da minha filha era como se fosse o último. (Isis, 20 anos, mãe de uma menina portadora de gastrosquise e atresia de cólon)

Não tinha certeza se ia dar certo, se ele ia conseguir ficar vivo, né?Sobreviver àquilo. (Estrela, 19 anos, mãe de um menino portador de gastrosquise)

Mas nem sempre a cirurgia consegue resolver todos os problemas apresentados pela condição clínica e cirúrgica da malformação, que pode ser uma patologia complexa e ter como causa síndromes que evoluem para a cronicidade. Neste momento, a mulher-mãe regride, reiniciando um ciclo de luto. A vivência da negação e todas as fases descritas por KüblerRoss ${ }^{16}$ são vividas e demandam novas estratégias de adaptação e superação:

Ficou aqui, não foi pra casa, botou o intestino pra dentro - não funcionou. (Radha, 19 anos, mãe de uma menina portadora de gastrosquise e atresia de íleo terminal)

Ah, eu tive receio porque eles falaram da carne morta que dá na... (nefrostomia) [...] aí eu fiquei mais 6 dias porque eu não sabia como é que era, aí me explicaram que não tinha problema nenhum, que não ia acontecer, porque ele precisava usar a bolsinha, aiffalaram que não tinha nada a ver e que provavelmente ia voltar ao normal. (Adit, 24 anos, mãe de um menino portador de válvula de uretra posterior e hidronefrose)

A imposição do que é belo, normal, faz com que a mulher tenha medo da cronicidade. Todas as expectativas são depositadas no ato cirúrgico e no cirurgião. A medicina acaba sendo vista como uma "máquina de fazer milagres" e recebe um poder que não é real, pois apresenta limitações pelo próprio estado da anomalia. Ver outras crianças com problemas similares é um movimento antagônico; ao mesmo tempo que é bom, pois a faz perceber que não é a única, causa desconforto pelo medo de que seu filho passe por situações similares de cirurgias consecutivas, gerando sofrimento, hospitalização prolongada e, por vezes, uso de tecnologias duras e levesduras de suporte (como gastrostomia ou traqueostomia, por exemplo). A internação vai criando expectativas na mulher, em seu cotidiano, o que a faz preocupar-se com o porvir do filho:

eu fico com medo de la ter que ficar aí o mesmo tempo das outras crianças. (Kamala, 22 anos, mãe de uma menina portadora de obstrução duodenal)

A assistência adequada à criança com malformação congênita demanda dos profissionais de saúde, além de treinamento técnico e científico, habilidade, sensibilidade e percepção para intervir na dimensão biopsicossocial e espiritual da criança e de seus familiares. ${ }^{17}$

Percebe-se, nas narrativas, angústia e dúvida, na ânsia de resolver os problema de saúde do filho. A necessidade de tentar iniciar a maternidade e o resgate do sentimento de normalização da criança está muito presente. Ao conhecermos esta realidade, podemos fundamentar a assistência de enfermagem e compreender melhor as preocupações e sentimentos vivenciados por essas mulheres.

\section{CONCLUSÕES}

0 estudo evidenciou a existência de sentimentos ambíguos e conflituosos vivenciados por mulheres-mães diante da cirurgia neonatal de seus filhos portadores de malformações congênitas.

A análise temática das narrativas apontou para a expectativa de normalização da criança e das trajetórias de vida das mulheres e sua família, gerando grande expectativa de correção da anomalia apresentada pelo RN. Ao passo que desejam e criam grande expectativa frente ao ato cirúrgico em si, também se sentem em conflito diante da hospitalização e vivenciam muitos medos (da morte, da anestesia e da cronicidade).

0 significado atribuído ao procedimento cirúrgico pelas mulheres-mães parece interferir diretamente em suas trajetórias de vida, no desempenho das funções maternas e na função de "ambiente" da mulher para com seu filho. Os sentimentos conflituosos de rejeição, a depressão e 0 desamparo estão presentes e precisam de suporte afetivo e apoio ao longo do processo, uma vez que estes fragilizam o vínculo afetivo entre a mulher-mãe e seu filho.

A partir do conhecimento destes sentimentos e da realidade enfrentada por essas mulheres, podemos tratar estratégias para um melhor acolhimento da mulher-mãe e seu filho. As narrativas proporcionam ao profissional a necessidade de maior sensibilidade associada ao cuidado técnico-científico, uma vez que estas mulheres estão 
altamente fragilizadas diante de uma experiência de vida muito singular.

Diante do exposto, cada mulher terá uma reação, uma forma de encarar a vivência cirúrgica de seu filho. A enfermagem deve entender que o cuidado deve ser individualizado, não existindo, assim, uma assistência a ser padronizada nestas situações. Os sentimentos e as necessidades da mulher, dia após dia, irão nos mostrar o cuidado de enfermagem a ser implementado.

A compreensão destes sentimentos deve ocorrer nos espaços de cuidado entre as mulheres-mães e a enfermagem, a fim de que mãe e bebê possam experimentar encontros e desencontros com a ajuda de profissionais, significando e ressignificando esta relação.

A enfermeira obstetra e neonatal deve atuar no processo de saúde-doença dos portadores de malformações congênitas cirúrgicas de forma ampliada, contemplando em sua assistência os aspectos técnico-científicos, mas, sobretudo, os aspectos emocionais presentes na mulher-mãe que vivencia sentimentos tão ambíguos em uma fase importante de construção de vínculos afetivos.

\section{REFERÊNCIAS}

1.Costa CMS, Gama SGN, Leal MC. Congenital malformations in Rio de Janeiro, Brazil: prevalence and associated factors. Cad Saude Publica 2006; 22 (11): 2423-431.

2. Ribeiro AM. Assistência ao recém-nascido com anomalias congênitas. In: Kopelman BI, Santos AMN, Goulart AL, Almeida MFB, Myoshi MA, Guinsburg R, editores. Diagnóstico e tratamento em neonatologia. São Paulo: Atheneu; 2004.p.45-55.

3. Guerra FAR , Llerena Junior JC , Gama SGN , Cunha CB , Theme Filha MM. Defeitos congênitos no município do Rio de Janeiro, Brasil: uma avaliação através do SINASC: 2000-2004. Cad Saude Publica. 2008 jan; 24(1):14049.

4. Couzin J. Desesperate measures. Science [on-line] 2006 ago; [citado 2010 fev 22]; 313: 904-07.Disponível em: http://www.sciencemag.org/ cgi/reprint/313/5789/904.pdf.

5. Joseph RA, Mackley AB, Davis CG, Spear ML, Locke RG. Stress in fathers of surgical neonatal intensive care unit babies. ethical issues in newborn care. advances in neonatal care. [on-line] 2007 dez; [citado 2008 dez 12]; 7(6): 321-25. Disponível em: http:// www.advancesinneonatalcare.org/pt/re/anc/abstract.00149525-

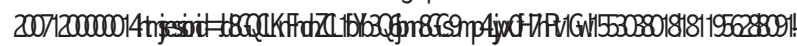

6. Rosa R da, Martins FE, Gasperi BL, Monticelli M, Siebert ERC, Martins NM. Mãe e filho: os primeiros laços de aproximação. Esc. Anna Nery. [on-line] 2010 mar; [citado 2010 out 14]; 14(1): 105-112. Disponível em: http://www.scielo.br/scielo.php?script=sci_arttext\&pid=S1414$81452010000100016 \& \mathrm{lng}=$ en. doi: 10.1590/S141481452010000100016 .
7. Winnicott DW. Os bebês e suas mães. São Paulo: Martins Fontes; 2006.

8. Bertaux D. Los relatos de vida: perspectiva etnosociológica. Barcelona: Ed Bellaterra; 2005.

9. Pope C, Mays N. Pesquisa qualitativa na atenção à saúde. $3^{\text {a }}$ ed. Porto Alegre: Artmed; 2009.

10. Canguillhem G. 0 normal e o patológico. $6^{\mathrm{a}}$ ed rev. Rio de Janeiro: Forense Universitária; 2009.

11. Helman CG. Cultura, saúde e doença. $4^{\mathrm{a}}$ ed. Porto Alegre: Artmed; 2003.

12. Coser LMS. Reconstruindo crianças: estudo etnográfico em um departamento de cirurgia pediátrica para bebês e crianças com anomalias congênitas [tese]. Rio de Janeiro: Instituto Fernandes Figueira; 2001.

13. Costa JB, Mombelli MA, Marcon SS. Avaliação do sofrimento psíquico da mãe acompanhante em alojamento conjunto pediátrico. Estud Psicol. [on-line] 2009 set; [citado 2010 jul 10]; 26 (3). Disponível em: < http:// uww.scielo.br/

14. Heneghan AM, Mercer MB, De Leone NL. Will mothers discuss parenting stress and depressive symptoms with their child's pediatrician. Pediatrics. [on-line] 2008 [citado 2010 fev 20]; 113(3): 460-67. Disponível em: http://pediatrics.aapublications.org/cgi/content/full/113/3/460.

15. Alves EGR. Morte em vida: mutilações e o processo do luto pela identidade perdida. In: Kovàcs ML. Fundamentos de psicologia. Morte e existência humana. Caminhos de cuidados e possibilidades de intervenção. Rio de Janeiro: Guanabara Koogan: 2008.p.126-47.

16. Kübler-Ross E. Sobre a morte e o morrer. $8^{a}$ ed. São Paulo: Martins Fontes; 2005.

17. Santos RS, Dias IMV. Refletindo sobre a malformação congênita. Rev Bras Enferm. 2005; 58 (5): 592-96.

\section{NOTA}

${ }^{\mathrm{a}}$ Recorte da Tese intitulada "O significado da cirurgia neonatal na presença de malformações congênitas: a visão materna para o cuidar de enfermagem" apresentada à Escola de Enfermagem Anna Nery- Rio de Janeiro Brasil, em 2010, para obtenção do Título de Doutora em Enfermagem. 